\title{
Probing "pop-out": Another look at the face-in-the-crowd effect
}

\author{
CAROL HAMPTON, DEAN G. PURCELL, LOUIS BERSINE, \\ CHRISTINE H. HANSEN and RANALD D. HANSEN \\ Oakland University, Rochester, Michigan
}

\begin{abstract}
C. H. Hansen and R. D. Hansen (1988) found that an angry face in a crowd of happy faces can be found faster than a happy face in a crowd of angry faces. They called this finding the face-inthe-crowd effect (FICE). The present experiments replicated this effect for nine-face crowds but not for four-face crowds. Hansen and Hansen concluded that their result was due to "pop out," because they found no reliable effect of crowd size for angry face targets. Contrary to prediction from the "pop out" hypothesis, we found that the position of the target face within the crowd had an effect on reaction time. Such positional effects demonstrate that subjects were scanning the face array to locate the target face. Examination of the literature on the perception of facial expression suggests that the FICE may be produced, at least in part, by the crowds scanned rather than by the target scanned for. The present paper suggests that conclusive evidence of "pop-out" should consist of both the absence of target-position effects and the conventionally accepted smallstimulus-set-size effects.
\end{abstract}

C. H. Hansen and R. D. Hansen (1988) report that the search time to locate a face within an array of other faces depends on the expression of the target face. An angry face in an array of happy faces was found faster than a happy face in an array of angry faces. They call their finding the face-in-the-crowd effect (FICE). In order to argue that "pop-out" is actually occurring, there must be little or no relationship between the number of items in the display and the time taken to find a target embedded in that display (Treisman \& Souther, 1985). This is essentially what C. H. Hansen and R. D. Hansen (1988) report. They suggest that faces are preattentively searched in parallel for features associated with a threatening expression, so that "an angry face in a happy crowd would pop out and not require an extensive, time-consuming, serial attentive search to discover its presence.... [On the other hand,] a happy face in an angry crowd would not be preattentively distinctive [because it is the only face whose expression does not represent a threatening emotion]; it would not pop out and discovering its presence would require a serial search of the faces" (p. 920).

There is another requirement that the data must meet if conclusive evidence for "pop out" is to be found. If "pop out" occurs, reaction time to locate the angry face should not be influenced by the position of the target face

Experiment 1 was conducted by Carol Hampton, as an honors independent study project, and Experiment 2 was conducted by Louis Bersine, as an independent study project. These projects were supervised by Dean G. Purcell. We wish to thank Eric Hiris for helping with data collection and analysis, and Alan L. Stewart for a critical review of the manuscript. This research was supported by a grant from the National Science Foundation (BNS-8517416). Carol Hampton is currently at Rutgers University, and Louis Bersine is currently at Eastern Michigan University. Correspondence should be sent to Dean G. Purcell, Department of Psychology, Oakland University, Rochester, MI 48309-4401. within the crowd. This is because there is no need to scan for a stimulus that pops out. Thus, position effects are not predicted for an angry face in a happy crowd. If position effects are found for both target-crowd types, then a factor other than "pop out" must account for the FICE.

The present study was designed to partially replicate C. H. Hansen and R. D. Hansen's (1988) third experiment concerning the FICE. It was also designed to test their application of the "pop out" hypothesis to explanation of the FICE. We used photocopies of one of the faces from Hansen and Hansen, but there were several departures from their procedures. We used one crowd size per experiment; Hansen and Hansen used crowd arrays of four and nine faces within the same subject. In Experiments 1 and 3 , the crowds contained nine faces in a $3 \times 3$ matrix. In Experiment 2, the crowds contained four faces in a $2 \times 2$ matrix. Also, although Hansen and Hansen used male and female faces, we used only their female face. The angry female face used by Hansen and Hansen had a large dark area just below its neck. We removed this possible stimulus confound so as to equate areas of light and dark for both happy and angry expressions. The most important departure from the procedure used by Hansen and Hansen was the recording of reaction time data for each of the face positions. This enabled a test of "pop-out" based on positional effects.

\section{EXPERIMENT 1}

\section{Method}

Subjects. The subjects were 19 naive volunteers from the psychology department subject pool.

Apparatus and Stimuli. The pictures of faces employed were photocopies of one of Hansen and Hansen's original stimuli, altered through the removal of a dark patch from the bottom of the angry face. Only copies that appeared identical in contrast and detail were selected for 
the study and mounted on cards. The female model was chosen over the male because of the superior quality of the female's expressions; both anger and happiness were more clearly portrayed on her face than on the man's (R. D. Hansen \& C. H. Hansen, 1988). The stimuli were presented as black patterns on a white background. The height and width of one block of nine faces were approximately $5.02^{\circ} \times 4.82^{\circ}$ of visual angle. The height and width of each individual face were approximately $1.32^{\circ} \times 1.03^{\circ}$ of visual angle. This matrix, or crowd, of faces was centered at the fixation point.

The stimuli were presented in an Iconix four-channel tachistoscope under the control of an Apple II + computer. The computer randomized trial sequences and recorded reaction times and errors. A dim fixation field containing a small black fixation spot was continuously present throughout the experiment. The luminance of this field was increased to $48 \mathrm{~cd} / \mathrm{m}^{2}$ for the $500 \mathrm{msec}$ prior to the onset of the crowd field. The crowd field was also set at about $48 \mathrm{~cd} / \mathrm{m}^{2}$. The walls of the well-lit experiment room were painted black and were at a luminance of about $1.17 \mathrm{~cd} / \mathrm{m}^{2}$

Procedure. The subject's task was to indicate whether or not he or she saw a discrepant face in the crowd of faces, by depressing one of the two outermost buttons on an eight-button panel. In all cases, the subject's preferred hand was used to indicate that there was a discrepant face in the crowd field. The nonpreferred hand was used to indicate that the crowd contained no discrepant face. This was a departure from the procedure of C. H. Hansen and R. D. Hansen (1988), who used a voice-keyed response.

The subjects were told to focus on a small black fixation point at the center of the dim fixation field. They were to initiate each trial by depressing both of the response buttons simultaneously when they heard a buzzing sound from the computer. When both buttons were released, the fixation field brightened prior to crowd presentation. At crowd onset, the fixation field dimmed to its original level until the next stimulus presentation. The crowd matrix remained visible until the subject responded. The subjects were instructed to respond "as quickly as you can without making mistakes," and each was given at least one short practice run before actually beginning the experiment. Error trials were randomized back into the trial order and rerun during the experiment. A complete session took 30-40 min to complete.

Data were recorded from eight positions; the center position in the display, while containing a crowd face, never contained a target face because the fixation point was presented at this spot. It was decided that no test of "pop out" occurred when the discrepant face appeared where the subject was already fixating. Each trial contained a crowd of either eight identical distractor faces and one discrepant face or simply a crowd of nine identical distractor faces. Trials were allotted as in C. H. Hansen and R. D. Hansen (1988). Independent variables of crowd type, target presence, and target position were investigated. Each subject was presented with 160 crowds -80 with a discrepant face, and 80 without. Forty of the presentations containing a discrepant face were happy crowds with an angry face, and the other half were angry crowds with a happy face. The remaining 80 trials contained no discrepant faces and were divided into $\mathbf{4 0}$ happy and $\mathbf{4 0}$ angry crowds. For each of the two crowd types a target face was displayed, in random order, five times in each of the eight possible target positions.

\section{Results and Discussion}

Error rates were under $5 \%$ on average, so an error analysis will not be presented here. The results are shown in Table 1. Consistent with C. H. Hansen and R. D. Hansen (1988), the data, averaged across position, show that an angry face in a crowd of happy faces is found faster $(1,414 \mathrm{msec})$ than a happy face is found in a crowd of angry faces $(1,573 \mathrm{msec})$. In the case of crowds without a discrepant face, crowds of happy faces are searched faster $(2,245 \mathrm{msec})$ than crowds of angry faces $(2,388 \mathrm{msec})$. Contrary to prediction from the "pop out" hypothesis, however, the position of the discrepant face
Table 1

Mean Reaction Times (Experiment 1)

for an Angry Face in a Happy Crowd and for a Happy Face in an Angry Crowd (underlined)

\begin{tabular}{lccc}
\hline & Left & Center & Right \\
\hline Top & 1282 & 1233 & 1319 \\
Middle & $\underline{1581}$ & $\underline{1325}$ & $\underline{1328}$ \\
& 1532 & & 1269 \\
Bottom & $\underline{1812}$ & & $\underline{1417}$ \\
& 1670 & 1505 & 1501 \\
& 1742 & $\underline{1625}$ & $\underline{1750}$ \\
\hline
\end{tabular}

Note-Position in the data matrix indicates discrepant face position in the crowd array.

produced an effect on reaction time for both types of crowd (angry vs. happy).

The reaction time data was treated with a repeated measures ANOVA. Prior to analysis, the Dixon test was used to eliminate outliers. There were significant effects of crowd type $[F(1,18)=20.27, p<.001]$, target position $[F(7,126)=7.96, p<.001]$, and target presence $[F(1,18)=76.36, p<.001]$. The two-way interaction of target presence $\times$ position was also significant $[F(7,126)$ $=5.50, p<.001]$. Neither the two-way interactions, of target presence $\times$ crowd $[F(1,18)=0.061]$, and crowd $\times$ position $[F(7,126)=1.67]$, nor the three-way interaction of target presence $\times$ crowd $\times$ position $[F(7,126)$ $=1.02]$ was significant. A simple-effects analysis of the target-present data demonstrated that crowd type had a significant effect on the time to find a discrepant face $[F(1,18)=10.54, p<.005]$. The same was true for the target-absent data $[F(1,18)=9.61, p<.01]$.

\section{EXPERIMENT 2}

In Experiment 1, we tested for "pop out" using crowds with nine faces. C. H. Hansen and R. D. Hansen's (1988) subjects received, in random order, trials with nine faces and with four faces. Experiment 2 was designed to test for the FICE and the effect of discrepant face position with a crowd of four faces.

\section{Method}

Subjects. The subjects were 12 naive volunteer subjects from the psychology department subject pool.

Apparatus and Stimuli. The apparatus was the same as in Experiment 1 . The stimulus cards were modified such that only four faces were presented on a given trial. These faces occupied the four corner positions of the stimuli used in Experiments 1 and 3. When a discrepant face was present, it occupied one of the four positions, with the distractors occupying the other three.

Procedure. The procedure was identical to that used in Experiment 1, with the exception that 10 trials were run under each condition.

\section{Results and Discussion}

The results of Experiment 2 can be seen in Table 2 . The average time to search a happy crowd for an angry face was $1,300 \mathrm{msec}$, while the average time to search an angry crowd for a happy face was $1,316 \mathrm{msec}$. As in Experiment 1, the time to search through targetless 
Table 2

Mean Reaction Times (Experiment 2)

for an Angry Face in a Happy Crowd

and for a Happy Face in an Angry Crowd (underlined)

\begin{tabular}{lll}
\hline & Left & Right \\
\hline Top & 1277 & 1210 \\
& $\underline{1232}$ & $\underline{1242}$ \\
Bottom & 1375 & 1339 \\
& 1402 & $\underline{1388}$ \\
\hline
\end{tabular}

Note-Position in the data matrix indicates discrepant face position in the crowd array.

crowds was less for a happy crowd $(1,360 \mathrm{msec})$ than for an angry crowd $(1,465 \mathrm{msec})$. A repeated measures ANOVA revealed significant main effects of target presence $[F(1,11)=5.42, p<.05]$, crowd type $[F(1,11)$ $=18.38, p<.002]$, and target position $[F(3,33)=5.07$, $p<.01]$. The two-way interactions of target presence $\times$ crowd type $[F(1,11)=10.98, p<.01]$, and target presence $\times$ target position $[F(3,33)=4.46, p<.01]$ were statistically significant. The two-way interaction of crowd type $\times$ target position was not significant $[F(3,33)$ $=2.56, p<.08]$. The three-way interaction of target presence $\times$ crowd type $\times$ target position was not significant $[F(3,33)=0.256]$.

A separate ANOVA on just the target-present trials failed to find a significant effect of crowd type $[F(1,11)$ $=1.159$ ], but target position continued to produce significant effects $[F(3,33)=5.81, p<.005]$. There was no crowd type $\times$ target position interaction $[F(3,33)=$ 1.27]. These results are very similar to those of Experiment 1, except that the FICE was not found.

\section{EXPERIMENT 3}

In Experiments 1 and 2, we found evidence that angry faces were not popping out of happy crowds, but were being scanned for. Both of these experiments differed from those of C. H. Hansen and R. D. Hansen (1988) in that a manual response was used to determine reaction time. Accordingly, Experiment 3 was a replication of Experiment 1 , but with a voice-activated relay as in Hansen and Hansen. All other aspects of the experiment were the same as in Experiment 1.

\section{Method}

Subjects. The subjects were 10 laboratory personnel. They were acquainted with C. H. Hansen and R. D. Hansen's (1988) hypothesis.

Apparatus and Stimuli. The apparatus was the same as in Experiment 1 , except that a voice-activated relay measured reaction time. The stimuli were the same as in Experiment 1.

Procedure. The procedure was identical with that of Experiment 1, except that the subjects responded verbally with "yes" or "no" to indicate the presence or absence of a discrepant face.

\section{Results and Discussion}

A repeated measures ANOVA revealed a pattern much like that found in Experiment 1. The main effects of target presence $[F(1,9)=36.74, p<.001]$ and crowd type $[F(1,9)=25.89, p<.01]$ were significant. The main effect of target position was not significant $[F(1,9)=1.99$, $p<.08$ ]. However, target position did interact with target presence $[F(7,63)=2.93, p<.025]$, as would be expected if there were position effects in the discrepantface-present conditions, but not in the discrepant-faceabsent conditions. Neither the two-way interaction of crowd type $\times$ target position $[F(7,63)=1.13]$ nor the three-way interaction of target presence $\times$ crowd type $\times$ target position $[F(7,63)=0.84]$ was significant. A simple-effects analysis showed that there was a significant effect of crowd type when targets were present $[F(1,9)=13.04, p<.01]$. As can be seen in Table 3, the results of this experiment were very similar to the results of Experiment 1. On average, angry faces in happy crowds were found faster $(1,328 \mathrm{msec})$ than happy faces in angry crowds $(1,404 \mathrm{msec})$. Again there were significant effects of target position within the nine-face array. When targets were not presented, the subjects scanned faster through happy crowds $(1,757 \mathrm{msec})$ than through angry crowds $(1,878 \mathrm{msec})$.

A separate ANOVA on just the target-present trials found, as in Experiment 1, a significant effect of crowd type $[F(1,9)=13.04, p<.01]$. Target position continued to produce significant effects $[F(7,63)=3.01, p<$ $.01]$. There was no crowd type $\times$ target position interaction $[F(7,63)=1.29]$. In Experiment 3, as in Experiment 1 , the type of crowd did have an effect on the time to find the target face, with faster times for an angry face in a happy crowd. However, this effect cannot be due to "pop out," for there are significant effects of target position for both crowd types.

\section{GENERAL DISCUSSION}

In Experiments 1 and 3, we found that an angry face in a happy crowd was found faster than a happy face in an angry crowd. It is clear that we replicated the FICE first described by C. H. Hansen and R. D. Hansen (1988). However, the fact that we found effects of target position regardless of the type of target searched for is not consistent with an explanation of the FICE based on "pop out." Such position effects are consistent with a face-by-face search of the crowd. That is, searches through a crowd of happy faces are faster than searches through a crowd of angry faces. In general, reaction times were faster for faces in the upper rows and rightmost columns of the crowd display.

It is not clear why the FICE was not found in Experiment 2; C. H. Hansen and R. D. Hansen (1988) report the FICE for their four-face crowds. It may be that when subjects are run only with four faces, as

Table 3

Mean Reaction Times (Experiment 3)

for an Angry Face in a Happy Crowd and for a Happy Face in an Angry Crowd (underlined)

\begin{tabular}{llll}
\hline & Left & Center & Right \\
\hline Top & 1198 & 1172 & 1164 \\
Middle & $\underline{1248}$ & $\underline{1267}$ & $\underline{1419}$ \\
& 1461 & & $\underline{1240}$ \\
Bottom & $\underline{1441}$ & & 1438 \\
& 1551 & 1403 & $\underline{1500}$ \\
\hline
\end{tabular}

Note-Position in the data matrix indicates discrepant face position in the crowd array. 
in Experiment 2, they adopt a strategy that eliminates the FICE. Nineface crowds may produce another strategy that generalizes to four-face crowds when they are randomly intermixed, as in Hansen and Hansen's study.

Although the present results concerning position effects are not consistent with a "pop out" explanation of the FICE, our results are consistent with the general literature regarding the perception of emotion in faces. When Stalans and Wedding (1985) used faces showing disgust, anger, surprise, and happiness, they obtained a significant effect of the emotion displayed. Identification latencies for positive affect were shorter than they were for negative affect. Stalans and Wedding (1985) hypothesized that "positive facial expressions (happiness, surprise) are more discrete and less ambiguous than the negative expressions (anger, disgust)," thus allowing subjects to process positive emotions faster and respond more quickly (Stalans \& Wedding, 1985, p. 222). This hypothesis is supported by Kirouac and Dore's $(1984,1985)$ studies, in which happiness was found to be the easiest facial expression to recognize over surprise, disgust, anger, sadness, and fear, in descending order of accuracy. Mandal and Palchoudhury (1985) achieved similar results. The fact that happy faces are more recognizable than other emotional faces tends to indicate that they are more distinct and less confusing, as Stalans and Wedding suggest. This premise would make degree of ambiguity, and not emotional valence, the deciding factor in speed of response. This last assertion should be tempered by the consideration that discreteness or ambiguity in facial expression may always be confounded with the emotion displayed.

McAndrew (1986) suggests another possible explanation for the present data. Angry faces might not just be intrinsically more ambiguous than happy faces, but simply be seen with less frequency than happy faces. Accordingly, we have less experience judging them and hence are slower to do so (McAndrew, 1986).

If, for whatever reason, happy faces are processed more quickly than angry faces, searching through a crowd of happy faces should take less time than searching a crowd of angry faces, whether or not those crowds contain a discrepant target face. This assumption would also explain Hansen and Hansen's targetless crowd effects as well as the present study's position data, since it assumes a serial search pattern. In summary, the FICE may, in large part, depend more on the crowd than on the face in that crowd.
It is important to note that C. H. Hansen and R. D. Hansen (1988) met the conventional requirements regarding the presence of "pop out." That is, the slope of their function relating reaction time to crowd size was very shallow. If such a shallow slope is truly diagnostic for "pop out," position effects should not have been found in the present experiments. The present experiments could not determine the reason why crowd size was not an effective variable in Hansen and Hansen's Experiment 3. They do, however, demonstrate the danger of relying exclusively on such a finding to justify an interpretation of "pop out," as well as the associated inference that preattentive, parallel processing has occurred.

\section{REFERENCES}

HANSEN, C. H., \& HANSEN, R. D. (1988). Finding the face in the crowd: An anger superiority effect. Journal of Personality \& Social Psychology, 54, 917-924.

Hansen, R. D., \& Hansen, C. H. (1988, August). Individual differences in facial expressions and empathy. Paper presented at the meeting of the American Psychological Association, Atlanta, GA

KIROUAC, G., \& Dore, F. Y. (1984). Judgement of facial expressions of emotion as a function of exposure time. Perceptual \& Motor Skills, $59,147-150$.

KirouaC, G., \& Dore, F. Y. (1985). Accuracy of the judgment of facial expression of emotions as a function of sex and level of education. Journal of Nonverbal Behavior, 9, 3-7.

Mandal, M. K., \& Palchoudhury, S. (1985). Perceptual skill in decoding facial affect. Perceptual \& Motor Skills, 60, 96-98.

MCANDREW, F. T. (1986). A cross-cultural study of recognition thresholds for facial expressions of emotion. Journal of Cross-Cultural Psychology, 17, 211-224.

Stalans, L. \& Wedding, D. (1985). Superiority of the left hemisphere in the recognition of emotional faces. International Journal of Neuroscience, 25, 219-223.

Treisman, A., \& Souther, J. (1985). Search asymmetry: A diagnostic for preattentive processing of separable features. Journal of $E x-$ perimental Psychology: General, 114, 285-310.

(Manuscript received May 3, 1989.) 